\title{
Risk Factors for Acute Respiratory Infections (ARI) Among Children Under Five Years in Bangladesh
}

\author{
Kazi Md. Abul Kalam Azad ${ }^{1}$ \\ School of Environmental Science and Management, Independent University, Bangladesh
}

Received 19 August 2008, in final revised form 20 November 2008

\begin{abstract}
Acute respiratory infection (ARI) is a major cause of childhood mortality and morbidity in Bangladesh. The aim of this study is to identify the significant risk factors for ARI in children less than five years of age. The data in this study comes from Bangladesh Demographic and Health Survey (BDHS) 2004. In this study, a child was considered as having experienced ARI if she or he had cough in the last two weeks preceding the survey with any one of the three symptoms of short but rapid breathing, difficulty of breathing or labored inspiration. Logistic regression was used on various independent variables to find the risk factors. Results showed that child's age, sex, body weight and Vitamin A deficiency were correlated with prevalence of ARI. Additionally mother's characteristics like age, malnutrition, education level, and family's socio-economic status were found to be associated. Recommendations include more specific knowledge of ARI to adolescent mothers from the lowest wealth quintile. A community service which could include home visiting for health education, supplementation of vitamin A, and advice would be an advantage if provided for poor or teenaged pregnant women. This in turn would reduce low birth weight incidence, and subsequently reduce incidence of ARI among these children.
\end{abstract}

Keywords: Acute respiratory infections (ARI); Risk factors; Infant; Child under 5 years; Bangladesh.

(c) 2009 JSR Publications. ISSN: 2070-0237(Print); 2070-0245 (Online). All rights reserved.

DOI: 10.3329/jsr.vlil.1055

\section{Introduction}

Acute respiratory infections (ARI) represent one of the main health problems in children less than five years of age and are the leading cause of death in developing countries. Among the total population of age under five, nearly one fifth of the total deaths are due to ARI [1-5]. Around $90 \%$ of ARI, deaths are generally due to a complication of the ARI usually (pneumonia) [2-4, 6, 7]. Half of the childhood mortality due to ARIs could be reduced if early detection and appropriate treatment could be provided [8]. Jennifer et al. estimated [7] that in 2000-2003 pneumonia accounted for $19 \%$ of the 10.6 million yearly

\footnotetext{
${ }^{1}$ E-mail: akazad71@gmail.com
} 
global deaths in children under five. Williams et al. [2] demonstrate that childhood mortality increases if death due to ARI increases.

Although the spread of ARI is worldwide, its impact is different in developed countries as opposed to developing ones. Whereas $1 \%$ to $3 \%$ of the deaths in children fewer than five years of age in developed countries are due to pneumonia, the disease causes $10 \%$ to $25 \%$ of these deaths in the developing countries. Access to health services is a key element in explaining this disparity: ARI is one of the main reasons for health consultations and hospitalizations in developing countries. Between $30 \%$ and $60 \%$ of medical consultations and $20 \%$ to $40 \%$ of hospitalization of children under five years of age are due to pneumonia [9].

Infants have the highest risk of pneumonia in their first three months of life. Nearly $70-75 \%$ of all deaths in infants are due to pneumonia. In both developing and developed countries, children of smokers exposed to passive smoking are more susceptible to pneumonia than those not exposed to cigarette smoke. Indoor air pollution is also strongly suspected of being an important contributor to ARI child death [4]. Victora [3] added a few socio-economic (particularly low income, parental low educational levels and place of residence), demographic (age, birth spacing and gender of child), nutritional and behavioral (including low birth weight, malnutrition, and lack of breast-feeding), and environmental (overcrowding, biomass-burning stoves) factors as the risk factors. Boys are more likely to suffer than girls, and infants are more vulnerable to suffer from ARI compared to toddler and child who may have the chance to build up some natural immunity [3].

In a recent study related to exclusive breastfeeding and death due to ARI among infants in a Dhaka slum, Arefeen et al. revealed [10] that compared with exclusive breastfeeding in the first few months of life, partial or no breastfeeding was associated with a 2.4-fold higher risk of death attributable to ARI. Malnourished children are at significantly higher risk of suffering from ARI compared with healthy children [5, 11-13]. This child malnutrition may be a combined effect of insufficient and improper food intake, improper treatment and care provided during and after sickness, lowered immune response and the potential for repeated suffering of infection from different diseases [14, 15]. Due to lower intake of adequate food, improper treatment and insufficient treatment, children from poor families grow up with weaker immune systems and increased risk of infection [16]. Vitamin A helps to decrease the severity of many infections, such as diarrhoea and measles [17-19].

\section{Data and Methodology}

\subsection{Study Design}

The data for this study come from the 2004 Bangladesh Demographic and Health Survey (BDHS 2004) that covered a nationally representative sample of 11,440 ever-married women of age 10-49 years and their children born 0-59 months prior to the survey date. The unit of analysis is the child. In order to reduce the recall bias in the BDHS survey, 
information regarding Antenatal Care (ANC), Post Natal Care (PNC), immunization, diseases etc. was asked only for the children of age less than 60 months. Therefore, a file was created for the sample of children of age 0-59 months including all variables of household and mother. A list of 6,498 surviving children (weighted frequency) was obtained from that file. Excluding missing, non-eligible (visitors in household), nonresponse cases for the questions related to ARI and child nutrition (height and weight without flagged); a final sample size of 5,466 children was obtained for this study.

\subsection{Variables}

\subsubsection{Dependent Variable}

In this study, the dependent variable is ARI, coded as 1 if the child suffered from ARI in the two weeks prior to the survey date and 0 otherwise. A child was considered as having experienced ARI if the mother reported that the child had a cough in the last two weeks preceding the survey date along with any one of three symptoms of: (i) short, rapid breathing; (ii) difficulty in breathing; (iii) chest in drawing [20].

\subsubsection{Independent Variables}

Independent variables were chosen based on prior knowledge of determinants of child morbidity and mortality and ARI in particular. The potential control and confounding variables such as household poverty, age of child, sex of child, stunting status of child (measured by height/age), vitamin A supplementation of child in last six months, mother's age, mother's Body Mass Index (BMI), mother's education and use of solid fuels for cooking were included. Most of the variables included in the study were included based on previous studies [3, 10, 12].

In the absence of income or consumption data, BDHS 2004 used household assets to construct a wealth index using principal components analysis [20, 21]. The wealth or household asset index was classified into five quintiles i.e. richest, richer, middle, poorer, and poorest. Childhood malnourishment and maternal BMI were operational zed using standard anthropometric measures of height and weight. The standard measurements were based on the U.S. National Centre for Health Statistics (NCHS) standard, recommended by the World Health Organization (WHO). Standard normal (Z score) was calculated for each variable. Details can be found from the survey BDHS 2004 [20]. Other independent variables are self-explanatory.

\subsection{Analysis}

The chi-square test was used during bivariate analysis for identifying variables associated with prevalence of ARI. Fourteen variables showed association with ARI. In the second stage, variables that were statistically significant during bivariate analysis were individually tested using logistic regression model. In this stage, fourteen variables were selected because of their odds ratio. According to their log likelihood figure, these 
independent variables were ranked from one to fourteen. Finally stepwise regression method was used to include and exclude variables at various stages according to their relative importance in the model and seven variables were selected as risk factors of ARI.

Logistic regression analysis using a standard statistical package (STATA 8) was used to estimate the effect of key explanatory variables on ARI among the children after controlling for the effect of other confounding variables.

\section{Results}

\subsection{Differential Analysis}

In this study, few variables were recoded in order to reduce the number of groups. A total of 1162 (21.3\%) of children less than five years of age suffered from ARI during the two weeks preceding the survey. The differential analysis of the socio-economic and demographic risk factors of ARI among children is shown in Table 1.

Table 1. Frequency distribution of ARI among children (0-59 months) on various socio-economic and demographic characteristics of Bangladesh (2004).

\begin{tabular}{|c|c|c|c|c|}
\hline \multirow{2}{*}{$\begin{array}{l}\text { Name of variable } \\
\text { Socio-economic }\end{array}$} & \multirow{2}{*}{$\begin{array}{c}\text { Total } \\
\text { Number }\end{array}$} & \multicolumn{2}{|c|}{$\begin{array}{l}\text { Among them, suffered from ARI in } \\
\text { last two weeks }\end{array}$} & \multirow[t]{2}{*}{$\begin{array}{l}\text { Chi square test } \\
\text { (P Value) }\end{array}$} \\
\hline & & $\mathrm{n}$ & $\%$ among total & \\
\hline Wealth index & & & & .000 \\
\hline Poorest & 1438 & 338 & 23.5 & \\
\hline Poorer & 1157 & 283 & 24.5 & \\
\hline Middle & 1052 & 235 & 22.3 & \\
\hline Richer & 941 & 174 & 18.5 & \\
\hline Richest & 878 & 133 & 15.1 & \\
\hline Mothers education & & & & .000 \\
\hline No education & 2134 & 455 & 21.3 & \\
\hline Primary & 1713 & 410 & 23.9 & \\
\hline Secondary & 1357 & 268 & 19.7 & \\
\hline Higher & 263 & 31 & 11.8 & \\
\hline Partner's education & & & & .005 \\
\hline No education & 2254 & 503 & 22.3 & \\
\hline Primary & 1503 & 330 & 22.0 & \\
\hline Secondary & 1230 & 257 & 20.9 & \\
\hline Higher & 476 & 72 & 15.1 & \\
\hline Source of drinking water & & & & .001 \\
\hline Piped & 338 & 49 & 14.5 & \\
\hline Tubewell (including sallow \& deep) & 4942 & 1062 & 21.5 & \\
\hline Other & 186 & 52 & 28.0 & \\
\hline Type of modern toilet facility & & & & .000 \\
\hline Septic tank/modern toilet & 449 & 65 & 14.5 & \\
\hline Other & 5017 & 1098 & 21.9 & \\
\hline Solid fuel & & & & .000 \\
\hline No & 398 & 55 & 13.8 & \\
\hline Yes & 5068 & 1108 & 21.9 & \\
\hline \multicolumn{5}{|l|}{ Demographic variables } \\
\hline Children's age in month & & & & .000 \\
\hline$<12$ & 1001 & 300 & 30.0 & \\
\hline $12-23$ & 1075 & 274 & 25.5 & \\
\hline $24-59$ & 3390 & 589 & 17.4 & \\
\hline
\end{tabular}




\begin{tabular}{|c|c|c|c|c|}
\hline Name of variable & Total & \multicolumn{2}{|c|}{$\begin{array}{l}\text { Among them, suffered from ARI in } \\
\text { last two weeks }\end{array}$} & $\begin{array}{l}\text { Chi square test } \\
\text { (P Value) }\end{array}$ \\
\hline Mother's age & & & & .000 \\
\hline $20+$ & 4619 & 911 & 19.7 & \\
\hline$<20$ & 847 & 252 & 29.8 & \\
\hline Mother's BMI $\left(\mathbf{k g} / \mathbf{m}^{2}\right)$ & & & & .000 \\
\hline$<18.5$ & 2059 & 488 & 23.7 & \\
\hline $18.5-24.9$ & 3100 & 638 & 20.6 & \\
\hline $25+^{(\mathrm{R})}$ & 287 & 36 & 12.5 & \\
\hline Sex of child & & & & .027 \\
\hline Girl & 2673 & 539 & 20.2 & \\
\hline Boy & 2793 & 624 & 22.3 & \\
\hline Place of delivery & & & & .002 \\
\hline Health facility & 507 & 83 & 16.4 & \\
\hline Other & 4959 & 1080 & 21.8 & \\
\hline Vitamin $A$ in last 6 months & & & & .000 \\
\hline No & 1499 & 420 & 28.0 & \\
\hline Yes & 3967 & 743 & 18.7 & \\
\hline Stunting & & & & .003 \\
\hline No & 3067 & 611 & 19.9 & \\
\hline Yes & 2399 & 552 & 23.0 & \\
\hline Wasting & & & & .004 \\
\hline No & 4727 & 977 & 20.7 & \\
\hline Yes & 739 & 186 & 25.2 & \\
\hline Total & 5466 & 1162 & 21.3 & \\
\hline
\end{tabular}

Note: Total for different sub-groups may not be equal to the grand totals due to missing value at different groups. Percentages are calculated on the basis of available frequencies.

\subsubsection{Socio-economic variables}

Prevalence of ARI significantly varied by wealth status of the household and was inversely related. Parental education played an import role to differentiate ARI among children where education has negative impact with ARI. It could be that educated parents were more aware about their child health, cared for their children properly, knew how to take prevention to avoid coughing, to reduce spread of infection and subsequently reduce the risk of ARI, immunized their children properly, fed vitamin A to their children, and gave warm clothes to the child if it was cold. Differential prevalence may be due to family earning and life style.

Source of drinking water and type of toilet facilities was found to be significantly related with ARI prevalence. Families with high socio-economic status are supposed to drink more piped water, and use hygienic toilets. These variations may be due to wealth status of the respondents. Use of solid fuel plays also important role in the child suffering from ARI.

\subsubsection{Demographic variables}

During the first three months of life, infants have the highest risk of pneumonia [4]. This evidence also showed that there was an inverse relation between age of child and 
prevalence of ARI. Infants (age $<12$ months) were suffering more from ARI than toddlers (age 12-23 months) and children (24-59 months).

Children's gender, place of delivery of the child (hospital $v$ home, hospital delivery has less chance of complications than home in Bangladesh), child's nutrition status (stunting of growth and muscle wasting) had significant effects on ARI in children. Height and weight compared to the normal BMI range of child is related with ARI.

Mother's age was also significantly related with the prevalence of ARI among children. If mother's age was less than 20, then the children had a higher chance of suffering from ARI. It may be such that teenage mothers mostly kept their concentration on their own happiness; gave more time to partner, less awareness about their child's health, less knowledge of how to take care of their child. No. of living children, birth order, no. of household members, total children ever born, preceding birth interval of child, and mother's tetanus injections before birth showed no significant effects on prevalence of ARI among children.

\subsection{Multivariate Analysis}

The regression was conducted by using stepwise logistic regression, including and excluding variables at various stages according to their relative importance in the model. Table 2 reveals that children's age was entered as the first variable in the model. This variable had three groups, infant (age $<12$ month), toddler (age 12-23 months), and child (24-59 months). For this variable, child was considered as reference category and it was found that an infant had 1.8 times and a toddler had 1.514 times significantly higher odds of suffering from ARI $(p<0.001)$ than a child.

Vitamin A consumption of children in the last six months was included in the model as a second variable and it was found that it had significant effect in the model. A child without taking vitamin A in last six months had $29 \%$ higher odds of suffering from ARI. However, a child of age less than six months cannot take vitamin A. In BDHS 2004, question regarding vitamin A supplement was asked only for the children of age 9-59 months. This may be the reason for infants suffering more in ARI. In order to reduce that effect, infant group was broken down into two sub groups, early infant (0-5 months) and late infant (6-11 months). The result was found to be the same for the subgroups but it reduced the magnitude to the likelihood of the model. Therefore, that break down of infants was not included into the model. Finally, the interaction terms for age of child and vitamin A supplementation were tested, but the effect was insignificant. Therefore, this term was not included in the final model.

Wealth index was included in the model. Effect of this variable was highly significant showing that children from lower socio-economic families suffer more from ARI than children higher socio-economic families. Wealth index was classified into five categories i.e. richest, richer, middle, poorer and poorest. In the first stage, only the wealth status variable was tested considering the richest quintile as the reference category. The statistical test showed that regression coefficients for poorest, poorer and middle quintiles are significantly similar. Then these three quintiles were merged into one category. After 
Table 2. Logistic regression of ARI among children (0-59 months) on various covariates of Bangladesh (2004).

\begin{tabular}{|c|c|c|c|c|}
\hline \multirow[t]{2}{*}{ Variables } & \multirow[t]{2}{*}{ Odds ratio } & \multirow{2}{*}{$\begin{array}{c}\text { Significance } \\
\text { ( } p \text { value })\end{array}$} & \multicolumn{2}{|c|}{$95 \% \mathrm{CI}$} \\
\hline & & & lower & upper \\
\hline \multicolumn{5}{|l|}{ Children’s age } \\
\hline$<12$ & 1.800 & 0.000 & 1.413 & 2.293 \\
\hline $12-23$ & 1.514 & 0.000 & 1.274 & 1.799 \\
\hline $24-59^{(\mathrm{R})}$ & 1 & & & \\
\hline \multicolumn{5}{|c|}{ Vitamin $A$ in last 6 months } \\
\hline $\mathrm{Yes}^{(\mathrm{R})}$ & 1 & & & \\
\hline No & 1.287 & 0.019 & 1.043 & 1.587 \\
\hline \multicolumn{5}{|l|}{ Wealth Index } \\
\hline Poor & 1.299 & 0.004 & 1.089 & 1.551 \\
\hline Well-off ${ }^{(\mathrm{R})}$ & 1 & & & \\
\hline \multicolumn{5}{|l|}{ Mothers' Age } \\
\hline$<20$ & 1.459 & 0.001 & 1.180 & 1.804 \\
\hline $20+{ }^{(\mathrm{R})}$ & 1 & & & \\
\hline \multicolumn{5}{|c|}{ Mother's BMI $\left(\mathrm{kg} / \mathrm{m}^{2}\right)$} \\
\hline$<18.5$ & 1.529 & 0.024 & 1.059 & 2.210 \\
\hline $18.5-24.9$ & 1.409 & 0.059 & 0.987 & 2.010 \\
\hline $25+{ }^{(\mathrm{R})}$ & 1 & & & \\
\hline \multicolumn{5}{|l|}{ Mothers' education } \\
\hline Primary or less & 1.203 & 0.011 & 1.043 & 1.386 \\
\hline Secondary $+^{(\mathrm{R})}$ & 1 & & & \\
\hline \multicolumn{5}{|c|}{ Height for age (stunting) } \\
\hline $\mathrm{No}^{(\mathrm{R})}$ & 1 & & & \\
\hline Yes & 1.187 & 0.033 & 1.014 & 1.389 \\
\hline
\end{tabular}

that the effect of merged group, richer and richest quintiles were checked and found that regression coefficients for richer and richest groups were statistically similar. Therefore, two rich categories were also merged into one category. Finally the wealth variable was constructed with two categories, namely, poor (with lowest $60 \%$ asset value) and well off (with higher $40 \%$ asset value). Compared to children from richest families, children from poorest families had $30 \%$ higher odds of suffering from ARI.

Respondent's (mother) current age was entered and its effect was significant meaning that if mother's age was less than 20 , children had $46 \%$ more odds $(p<.001)$ of suffering from ARI.

Partner's education was entered into the model but its effect was insignificant. Therefore this variable was excluded from the model. Then respondents' education was added in the model and found to have a significant effect. This result showed that child born to mothers with primary or uneducated had significantly $20 \%$ higher odds of 
suffering from ARI compared to children born to mothers with secondary or higher education.

Type of hygienic toilet was entered into the model and its effect was found insignificant, and the same was observed for delivery in health facility, source of drinking water, type of cooking materials (solid fuel). These variables were deleted from the model. As these variables were related to wealth status of a family, effect of these variables was controlled by the wealth status of family and these variables became insignificant.

Chronic nutrition status of children explained by stunting was included in the model and its effect was found to be significant. A child with stunted growth has $19 \%$ more odds of suffering from ARI $(p<.001)$ compared to children without stunted growth.

\section{Conclusion}

Suffering due to ARI differed for socio-economic and demographic characteristics. This study found that infants were most vulnerable group followed by toddlers and children. The results of the present study confirmed previous findings that showed wealth status of a family, mother's education, Vitamin A deficiency, nutrition of the child (proxied by stunting), are the risk factors for ARI among children under five [3, 19, 22]. Therefore to reduce the incidence of ARI among children under five and to reduce the childhood death due to ARI, health workers must promote Vitamin A supplementation for all in this group. Family members have to seriously supervise their child's Vitamin A intake.

This study demonstrated that children born in lower socio-economic groups suffered more from ARI than the children born in higher socio-economic groups. Data showed that proportion of treatment sought from skilled professional parents increased if the wealth status of households improved. Also children of secondary and higher educated mother showed less chance of suffering from ARI compared with children of primary or less educated mother. Socio-economic status is also an important factor for treatment seeking from qualified doctor. Therefore, if rapid breathing and labored inspiration were recognized in a timely manner, most deaths from ARI's could be averted where appropriate services were available [8].

This study also revealed that some mother's characteristics like teenage pregnancy, lower BMI and lower education are the risk factor for children suffering from ARI. Early marriage and early child bearing rate is higher among women coming from families with poor socio-economic status [23, 24]. Poverty is one of the major factors leading early marriage. Where poverty is acute, a young girl may be regarded as an economic burden. Early marriage is working as a barrier to higher education among women. Evidence shows that secondary or higher educated women are less likely to marry during adolescence [24]. Education is associated with an increase in the age of marriage and childbearing. Apart from biological factors, early marriage and childbearing are associated with health risks that mean an early termination of a woman's education resulting to limited knowledge of reproductive health and general health therefore lower probability of utilizing maternal and child-health services [25]. Adolescents' mothers are more likely to 
give birth to preterm and low birth weight children compared with older peers. This is mainly associated with lower education, poor maternal nutrition (lower BMI), reinforcing the point that adolescents are 'unready' for childbirth [23]. Because of early marriage, these adolescent women are bearing children at a young age which in itself is a risk factor of premature birth and low birth low-birth-weight child. Thus early marriage of a family leads to their children suffering ARI. Government could take measures to increase the legal age for marriage to reduce this problem. The minimum age for leaving school could also be increased.

The results of this study have implications for the strategy to implement primary healthcare programme in Bangladesh. There is a need to implement an integrated package of immunization and Vitamin A supply and other childcare programmes to reduce ARI among children. It is necessary to provide education to women as children of educated mother showed less chance of suffering from ARI. There is also a need to focus health education messages both at school and to teen age, uneducated or less educated; poor mothers so that they will acquire more knowledge about ARI and parents will be more likely of when to seek medical assistance for ARI. Community care promoting health education, good nutrition, vitamin A supplementation and treatment service for ARI could be provided among the vulnerable groups, especially for poor or teenage pregnant women in order to reduce number of LBW child. Home visiting service could also be beneficial for children born to families with lower socio-economic status, to mothers with lower education and to teenage mothers in order to reduce ARI among these children and to reduce deaths from this condition.

\section{Acknowledgements}

The study was undertaken as a thesis work for the author's Master of Public Health (MPH) degree. Special acknowledgement is due to Dr. Nashid Kamal, Professor, Department of Population and Environment, Independent University, Bangladesh for her inspiration to conduct such a study.

\section{References}

1. I. A. Kristensen and J. Olsen, South African Medical Journal 96 (7), 633 (2006).

2. B. G. Williams, E. Eleanor, C. Boschi-Pinto, J. Bryce, and C. Dye, Lancet Infect Dis. 2, 25 (2002). doi:10.1016/S1473-3099(01)00170-0

3. C. Victora, Integrated Management of Childhood Illness (Pan American Health Organization [PAHO], Division of Disease Prevention and Control, Communicable Diseases Program, 41 1999).

4. World Bank, Acute Respiratory Infections (1993).

5. F.W. Denny and F. A. Loda, Am. J. Trop. Med. Hyg. 35 (1), 1 (1986).

6. World Health Organization (WHO), Acute Respiratory Infections, 2006.

7. B. Jennifer, B. P. Cynthia, S. Kenji, and R. E. Black, Lancet 365, 1147 (2005). doi:10.1016/S0140-6736(05)71877-8

8. A. Hadi, Bulletin of the World Health Organization 81 (3), 183 (2003). 
9. Y. Benguigui, Integrated Management of Childhood Illness (Pan American Health Organization [PAHO], Division of Disease Prevention and Control, Communicable Diseases Program, 23 (1999).

10. S. Arifeen, R. Black, G. Antelman, A. Baqui, and L. Coulfield, Pediatrics 108 (4), E67 (2001). doi:10.1542/peds.108.4.e67

11. M. M. Rahman and A. M. Rahman, Bangladesh Med. Res. Counc. Bull. 23 (2), 47 (1997).

12. P. Chabra, S. Garg, S.K. Mittal, and S. Chhabra, Indian J of Maternal and Child Health 8 (1), 13 (1997).

13. P. V. Kaushik, J. V. Singh, M. Bhatnagar, S. K. Garg, and H. Chopra, Indian J of Maternal and Child Health 6 (3), 71 (1995).

14. R. Hong, E. B. James, and A. B. Jose, Int. J. for Equity in Health 5 (December 5), 15 (2006).

15. D. L. Pelletier, Dept. of Economic and Social Affairs, Population Division, UN, (1998).

16. A. L. Rice, L. Sacco, A. Hyder, and R. E. Black, Bull World Health Organ. 78, 1207 (2000).

17. M. M. Rahman, D. Mahalanabis, J. O. Alvarez, M. A. Wahed, M. A. Islam, D. Habte, M. A Khaled, J. Nutr. 126 (3), 628 (1996).

18. A. Pandey and A. K. Chakraborty, Indian J. Public Health 40 (1), 13 (1996).

19. I. Sumarno, Doctoral dissertation, University of Michigan, UMI Dissertation Services, UMI No. 166 (1994).

20. National Institute of Population Research and Training (NIPORT), Mitra and Associates, and ORC Macro (2005).

21. S. O. Rustein and K. Johnson, DHS Comparative Report No. 6, Calverton, Maryland, USA: ORC Macro (1994).

22. A. K. Mbonye, J. Health Popul. Nutr. 22 (1), 52 (2004).

23. UNICEF: Innocenti Digest 7 (Mar), 1 (2001).

24. S. Susheela and R. Sarma. International Family Planning Prospective 22, 148 (1996). doi:10.2307/2950812

25. M. K. Choe, S. Thapa, and S. I. Achmad. Asia-Pacific Population and Policy 58 (July), 1 (2001). 